\title{
Titania aerogels: Preparation and photocatalytic tests
}

\author{
B. Malinowska, ${ }^{1, \dagger}$ J. Walendziewski, ${ }^{1, \ddagger}$ D. Robert, ${ }^{2, *}$ \\ J. V. Weber, ${ }^{2, * *}$ and M. Stolarski ${ }^{1}$ \\ ${ }^{1}$ Wroclaw University of Technology, Institute of Chemistry and Technology Petroleum \\ and Coal ul. Gdanska 7/9, 50-344 Wroclaw, Poland \\ ${ }^{2}$ Laboratoire de Chimie et Applications (EA, 3471), Université de Metz, \\ Rue Victor Demange, 57500 Saint-Avold, France
}

\begin{abstract}
Titania aerogels are suggested as promising photocatalysts [1]. In the present study aerogels were synthesised by sol-gel method combined with supercritical drying. Tetraisopropyl orthotitanate was used as a precursor, anhydrous methanol and isopropanol as solvents. Three aerogels were prepared using different ways of synthesis. Volumes and surface areas of micro- and mesopores of each aerogel were determined. XRD and SEM analyses were carried out. For comparison analyses were also performed for $\mathrm{TiO}_{2} \mathrm{P}_{25}$ Degussa. Aerogels' BET surface areas ranged from 73 to $96 \mathrm{~m}^{2} \mathrm{~g}^{-1}$. They indicate the crystalline structure of anatase. Finally photocatalytic tests were performed using water solution of p-chlorophenol and 4-hydroxybenzoic acid. Experiments were carried out in the Solar box simulating sun irradiation and on location. Aerogel Z513 prepared using 30\% of precursor (tetraisopropyl orthotitanate) in isopropanol as a solvent indicates the best photocatalytic activity towards p-chlorophenol while Z516 prepared using 60\% of precursor in methanol towards 4-hydroxybenzoic acid.
\end{abstract}

\section{INTRODUCTION}

Photocatalysis is a widespread domain of science combining chemistry, physics, medicine, environmental protection, power industry etc. Although a huge number of publications concerning that field, there are still a lots of questions and inaccuracies. In particular, photocatalyzed water treatment is the subject of great study. The application of photocatalysis to water treatment includes: ground water detoxification and wastewater decontamination where the appropriate expanse and powerful sun irradiation are indispensable. Besides those possibilities photocatalysis can find applications in ultrapure water production, as domestic water purifier or in the disinfection [2].

Semiconductors ( $\mathrm{ZnO}[3,4], \mathrm{CdS}, \mathrm{ZnS}$ [5], $\mathrm{WO}_{3}$ [6], $\left.\mathrm{TiO}_{2}[4,7-11]\right)$ are well known effective photocatalysts. They absorb beam of photons and while the energy of irradiation is higher or equal difference between energy of the conduction band and the valence band electron transition occurs. Electrons on the conduction band and valence band holes are generated. The commercial photocatalyst is titanium dioxide due to its high activity, stability and low cost. The energy of conduction band of $\mathrm{TiO}_{2}$ in water solution amounts to $-0.1 \mathrm{eV}$ while energy of valence band $+3.1 \mathrm{eV}$. Conduction band electrons are reduction centres while the valence band holes oxidation centres that after reaction with water

\footnotetext{
${ }^{\dagger}$ E-mail: Malinowska@nafta1.nw.pwr.wroc.pl

‡E-mail: Walendziewski@nafta1.nw.pwr.wroc.pl

*E-mail: Didier.Robert@iut.univ-metz.fr

**E-mail: jvweber@iut.univ-metz.fr
}

produce hydroxyl radicals-strong oxidising agents $[12,13]$. Thus excitation of suspended $\mathrm{TiO}_{2}$ in the aqueous solution, leads to redox reactions in the region around each particle. Hence contaminants present in the solution can be either oxidised or completely mineralised. In spite of the properties of titanium dioxide a photocatalyst of better characteristics is required. It is necessary to synthesise much more active photocatalyst of long lifetime, easily regenerated. As one of the possible solution titania aerogels are suggested.

Aerogels are porous materials. They have low density, high surface area and high pore volume [1, 14]. They are produced by sol-gel methods followed by drying under supercritical conditions. There are lots of possibilities of aerogel synthesising. However, the main principle of aerogel preparation consists of five steps: homogenisation of precursor and alcohol, hydrolysis, ageing, drying and calcination. Literature data point to the usage of the aerogels as photocatalysts. Sen and Vannice [15] prepared titania aerogels and decomposed paraffins, olefins and alcohols into ketones and aldehydes in the presence of UV irradiation. Ahmed and Attia [11] photodegradated cyanide wastes in water in the presence of $\mathrm{TiO}_{2}-\mathrm{SiO}_{2}$ aerogels. Next Deng et al. synthesised titania aerogels and checked them successfully in photooxidation process of phenol [16].

The objective of the research is to find optimal synthesis conditions to obtain catalysts of better photocatalytic activities. Physicochemical properties of all catalysts were determined. p-Chlorophenol and 4hydroxybenzoic acid were chosen as model contaminants of water solution. 


\section{EXPERIMENTAL}

2.1. Reagents. Tetraisopropyl orthotitanate (Fluka), anhydrous methanol, isopropanol (Aldrich), p-chlorophenol (Aldrich), titanium dioxide P25 (Degussa). All reagents were used as received.

2.2. Preparation of aerogels. Titania alkoxide gels were obtained using different concentrations of tetraisopropyl orthotitanate, appropriate solvent (anhydrous methanol, isopropanol) and water. The hydrolysis process lasted $2 \mathrm{~h}$ whereas ageing step $24 \mathrm{~h}$. Then the wet gels were placed in an autoclave for drying under supercritical conditions. In order to prevent gels from collapse at the heating-up stages, initially the autoclave was pressurised with nitrogen to about $80 \mathrm{~atm}$. Figure 1 depicts temperature and pressure cycles versus time during supercritical drying. The last step of aerogel preparation was calcination at $400^{\circ} \mathrm{C}$ for $5 \mathrm{~h}$.

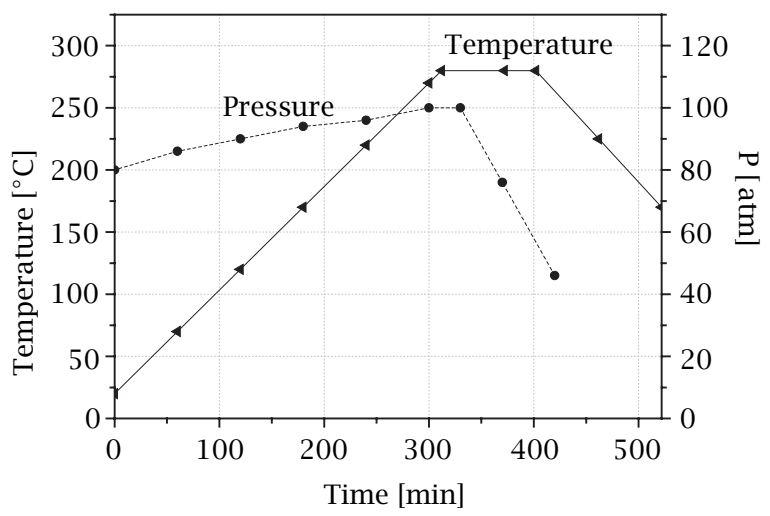

Figure 1. Temperature and pressure cycles versus time during supercritical drying.

\subsection{Physicochemical properties.}

- Crystalline structure of the aerogels were measured by X-ray diffraction method (XRD) using Siemens D5005 diffractometer (Co $\mathrm{K}_{\alpha}$ irradiation, filter Fe, $45 \mathrm{kV}, 35 \mathrm{~mA}$ ).

- Scanning electron microscopy analyses (SEM) were performed using Joel JSM 5800 LV microscope, while samples were covered by thin layer of gold.

- Size of micropores and mesopores, surface areas $\mathrm{S}_{\mathrm{BET}}$ were determined using benzene adsorption/desorption method.

- Bulk densities of the aerogels were determined.

2.4. Photocatalytic tests. $60 \mathrm{ppm}$ and $100 \mathrm{ppm}$ aqueous solutions of $\mathrm{p}$-chlorophenol were used at the photocatalytic tests. Tests were conducted in the Solar box ATLAS SUNTEST CPS+ simulating natural radiation (light source vapour Xenon lamp, $400 \mathrm{~W}$ ) and on location (light source sunlight). In the first case $500 \mathrm{ml}$ of the examined solution (60 ppm) and $1 \mathrm{~g}$ cat./1 were magnetically stirred and irradiated for $4 \mathrm{~h}$. In the second case $100 \mathrm{ml}$ of the solution with $1 \mathrm{~g}$ cat./1 was exposed to sunlight for $2.5 \mathrm{~h}$. Reaction mixtures were maintained in suspension by magnetic stirring. Before irradiation reaction mixtures in the first case were magnetically stirred for $30 \mathrm{~min}$ in the dark to achieve equilibrium state, while in the second case for $15 \mathrm{~min}$. Each sample was filtrated $(0.2 \mu \mathrm{m}$ nylon membranes, Supelco) and analysed using UV-Vis spectrometer (Shimadzu spectrometer, $200 \mathrm{~nm}<\alpha<500 \mathrm{~nm}$ ) in the first case and gas chromatography fitted to flame ionisation detector (GC Hewlett Packard 48990D FID, capillary column HP-5) in the second.

Photocatalytic tests using 4-hydroxybenzoic acid $(4 \mathrm{HBz})$ were carried out in the solar box. $100 \mathrm{ppm}$ of the aqueous solution of $4 \mathrm{HBz}$ acid was prepared. Photocatalytic processes were conducted as in the case of p-chlorophenol. Samples after filtration were analysed using High Performance Liquid Chromatography (HPLC Waters 600 pump and 996 photodiode array detector). In the case of the aerogel Z516 (60\% of precursor in methanol) Total Organic Carbon analyses were performed.

\section{RESULTS AND DISCUSSION}

3.1. Catalyst characterisation. The procedure of aerogel synthesis resulted in a porous, white, opaque powder catalysts. Table 1 presents: prepared aerogels, amounts of precursor and solvent used in the syntheses, critical temperatures and pressures of solvents.

Size of the micropores, mezopores, surface areas and bulk densities of the aerogels were determined (Table 2). The determinations were also carried out for commercial photocatalyst- $\mathrm{TiO}_{2} \mathrm{P} 25$ Degussa, concerned as the best one.

Results of bulk densities point at aerogels as very light materials. Bulk density of commercial $\mathrm{TiO}_{2}$ P25 is twenty times bigger, while pure anatase amounts to $0.9091 \mathrm{~g} \mathrm{~cm}^{-3}$. Dagan and Tomkiewicz [1] synthesised titania aerogels using $\mathrm{HNO}_{3}$ as a catalysts. Bulk densities of the aerogels ranged from 0.3 to $1.0 \mathrm{~g} \mathrm{~cm}^{-3}$, depending on temperature of supercritical drying and time of the calcination .

Schneider and Baiker studied aerogels prepared by sol-gel method combined with supercritical drying at the high temperature and calcinated at $350{ }^{\circ} \mathrm{C}$ [17]. They determined that pore size maxima ranged from $25 \mathrm{~nm}$ to $60 \mathrm{~nm}$ and the BET surface areas have been changing from 68 to $91 \mathrm{~m}^{2} \mathrm{~g}^{-1}$. Aerogels in the present study were synthesised under similar conditions. Technique used to determine pore size distribution allowed indicate volumes and surfaces of micro- $(0.4 \mathrm{~nm}-2 \mathrm{~nm})$ and mesopores $(2 \mathrm{~nm}-50 \mathrm{~nm})$ only. The total volume of 
Table 1. Parameters of titania aerogels preparation.

\begin{tabular}{lccccc}
\hline Aerogel & $\begin{array}{c}\text { Concentration of IZPT } \\
\text { in solvent [\%] }\end{array}$ & $\begin{array}{c}\text { Molar ratio of } \\
\mathrm{H}_{2} \mathrm{O}: \text { IZPT }+ \text { solvent }\end{array}$ & Solvent & $\begin{array}{c}\text { Critical temperature } \\
\text { of solvent }\left[{ }^{\circ} \mathrm{C}\right]\end{array}$ & $\begin{array}{c}\text { Critical pressure of } \\
\text { solvent [ atm.] }\end{array}$ \\
\hline Z513 & 30 & $4: 1$ & isopropanol & 243 & 53 \\
Z514 & 30 & $4: 1$ & methanol & 240 & 78.7 \\
Z516 & 60 & $4: 1$ & methanol & 240 & 78,7 \\
\hline
\end{tabular}

Table 2. Characterisation of size of the micro- and mesopores of the catalysts.

\begin{tabular}{llcccc}
\hline Catalyst & Characterisation & $\begin{array}{c}\text { Volume of micro- and } \\
\text { mesopores cm } \mathrm{g}^{-1}\end{array}$ & $\begin{array}{c}\text { Surface of micro- and } \\
\text { mesopores m } \mathrm{g}^{-1}\end{array}$ & $\begin{array}{c}\text { S } \\
\text { BET }\end{array}$ & $\begin{array}{c}\text { Bulk density } \\
\mathrm{g} \mathrm{cm}^{-} 3\end{array}$ \\
\hline $\mathrm{Z513}$ & 30\% IZPT, isopropanol & 0.15 & 139 & 73 & 0.2067 \\
$\mathrm{Z514}$ & 30\% IZPT, methanol & 0.249 & 187 & 96 & 0.1401 \\
$\mathrm{Z} 516$ & 60\% IZPT methanol & 0.255 & 171 & 83 & 0.2099 \\
$\mathrm{TiO}_{2}$ & P25 Degussa & 0.05 & 61 & 36 & 4.3800 \\
\hline
\end{tabular}

them changes from 0.15 to $0.255 \mathrm{~cm}^{3} \mathrm{~g}^{-1}$. It appeared that the largest pore volume indicates aerogel prepared from the most concentrated precursor $(60 \% \mathrm{wt}$.) in anhydrous methanol, while the one, prepared using isopropanol as a solvent, indicates the smallest pore volume. Pore structure determined for two aerogels prepared from methanol are similar. The conclusion can be drawn that volume of micro- and mesopores depend on solvent used in synthesis process. However, it must be added that aerogels are mainly mesoporous materials [17]. Next results point at nonporous structure of $\mathrm{TiO}_{2} \mathrm{P} 25$ (volume of micro- and mesopores amounts to $0.05 \mathrm{~cm}^{3} \mathrm{~g}^{-1}$ ). Taking into consideration BET surface areas and surfaces of micro- and mesopores it appeared that the highest values indicates aerogel Z514 and the lowest one $\mathrm{Z} 513$. Surface of $\mathrm{TiO}_{2} \mathrm{P} 25$ is about three times lower in comparison to aerogels.

XRD analyses identified only tetragonal anatase crystalline structure in all aerogels. The amount of anatase structure changes in the following order: Z513 > Z516 > Z514. Calcination temperature up to $440{ }^{\circ} \mathrm{C}$ results in a rise of the anatase structure, while at the higher temperature treatment rutile crystallites appear [18, 19]. However aerogels without hightemperature treatment indicates amorphous structure [20]. In the case of titanium dioxide P25 anatase and rutile phases are present, whereas the content of anatase crystalline phase is bigger than indicates Z13 aerogel.

Images received from scanning electron microscopy (SEM) point at differences of size particles of the tested catalysts (Figure 2).

The images were magnified 30,000 times. Titanium dioxide P25 indicates the smallest agglomerates of $<50 \mathrm{~nm}$ size. There is a big difference between structure of the aerogels. The aerogel Z513 (30\% IZPT, isopropanol) consists of agglomerates of on average $500 \mathrm{~nm}$ size. In the case of aerogels, prepared with usage of anhydrous methanol, agglomerates are of
$<100 \mathrm{~nm}$ size. Above results prove that structure of the aerogel depends on solvent used in the initial step of synthesis process. However, it does not depend on the concentration of precursor in the solvent.

3.2. Photocatalytic tests. Obtained aerogels and commercial titanium dioxide were checked in the photodegradation of p-chlorophenol in the aqueous solution. Two photocatalytic sets were examined. The first one was a Solar box with xenon lamp $(400 \mathrm{~W})$ as light source. Figure 3 depicts obtained results.

The best photocatalytic properties indicated aerogel Z513 (30\% IZPT, isopropanol). After 3 hours of degradation there was no p-chlorophenol detection. In the case of aerogels Z514 and Z516 ca. 25\% of initial concentration of $\mathrm{p}$-chlorophenol was detected after 4 hours of irradiation. Titanium dioxide P25 indicated photocatalytic properties similar to Z513.

$\mathrm{Z} 513$ as the aerogel of the best activity and $\mathrm{TiO}_{2} \mathrm{P} 25$ were chosen to the next experiments. Photocatalytic tests this time were carried out on location, the light source was sunlight. Received results are shown in the Figure 4.

Obtained results were the next proofs that photocatalytic activities of $\mathrm{Z} 513$ and $\mathrm{TiO}_{2}$ P25 are similar although their structures (pore volumes, $S_{\text {BET }}$ surface areas, size of the particles, crystalline forms) are quite different. Experiments performed in the dark point out the adsorption capability of the aerogel, while $\mathrm{TiO}_{2}$ does not reveal any adsorption of p-chlorophenol after 2 hours of the test.

On this level of study we can not take into consideration entirely mineralization of the contaminant. p-Chlorophenol are decomposed into intermediates products as the effect of oxidation. Therefore total organic carbon analyses are in the curse now. There are some literature data pointing out that $\mathrm{p}$ chlorophenol decomposition occurs rather fast and results in quinone [21], hydroquinone [9] or association 


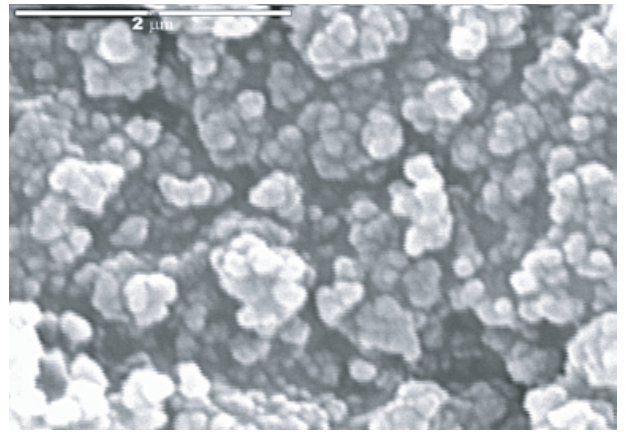

(a)

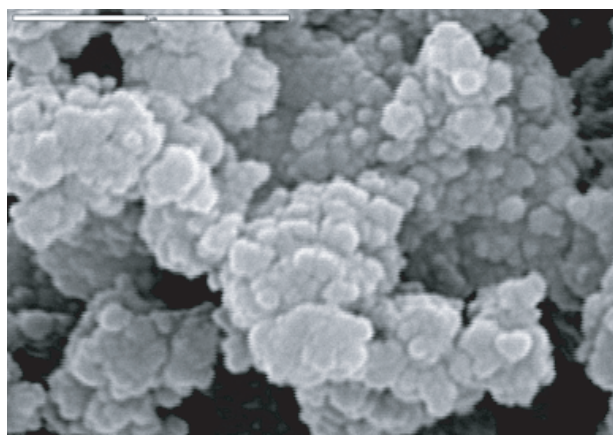

(c)

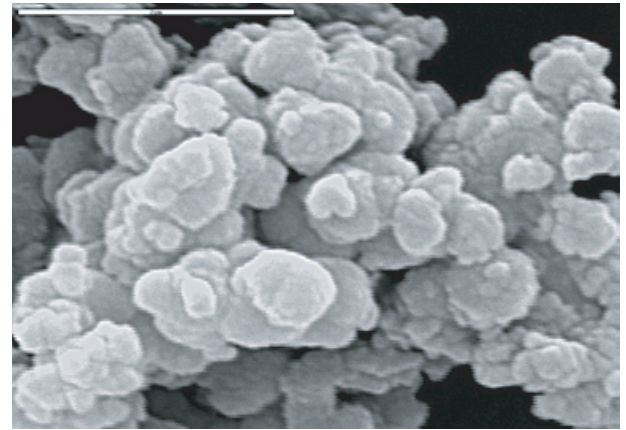

(b)

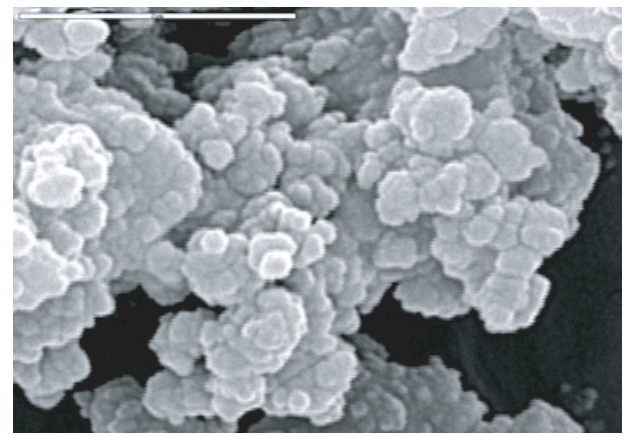

(d)

Figure 2. SEM images of the catalysts: (a) $\mathrm{TiO}_{2} \mathrm{P} 25$ Degussa, (b) Z513, (c) Z514, (d) Z516.

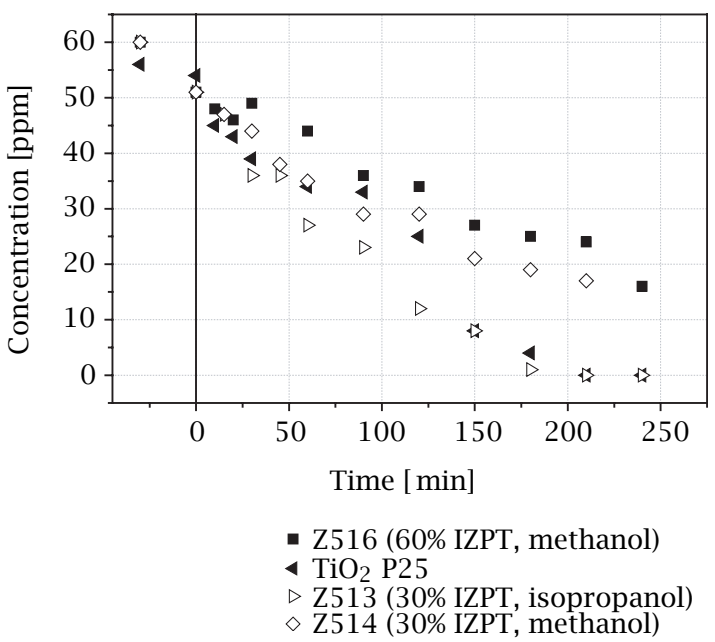

Figure 3. Kinetics of photodecomposition of $60 \mathrm{ppm}$ aqueous solution of p-chlorophenol (light source xenon lamp, $400 \mathrm{~W})$.

phenoxy radicals and intermediates present in the solution. First step of p-ch lorophenol decomposition is dehalogenation due to weakness of $\mathrm{C}-\mathrm{Cl}$ bond [22]. However photodegradation of different organic compounds depends on their reactivity towards $\mathrm{OH}^{\bullet}$ radicals [9] which are photogenerated in the aqueous solution or directly on the surface of the catalyst. The

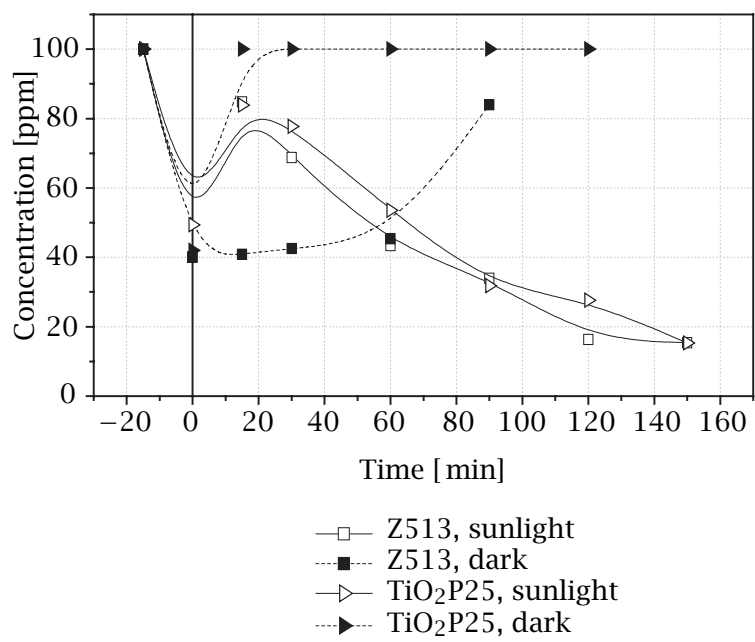

Figure 4. Kinetics of photodecomposition of $100 \mathrm{ppm}$ aqueous solution of p-chlorophenol, light source sunlight, adsorption/desorption tests (experiments carried out in the dark).

another very significant dependence is: relationship between contaminant and a kind of catalyst, what was confirmed by the study of 4-hydroxybenzoic acid photodecomposition (Figure 5).

The best photocatalytic activity in the case of 4-hydroxybenzoic acid degradation indicated aerogel 


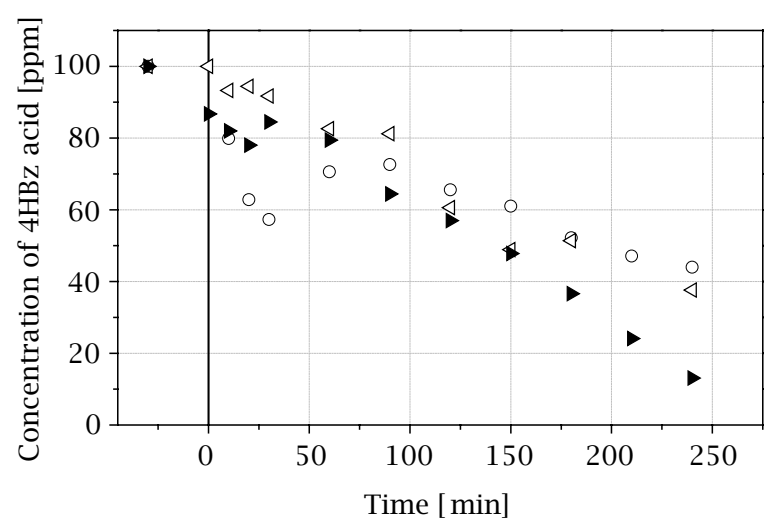

○ Z513 IZPT 30\%, isopropanol

$\triangleleft \mathrm{TiO}_{2}$ Degussa

Z Z516 IZPT 60\%, methanol

Figure 5. Kinetics of photodecomposition of $100 \mathrm{ppm}$ aqueous solution of 4-hydroxybenzoic acid.

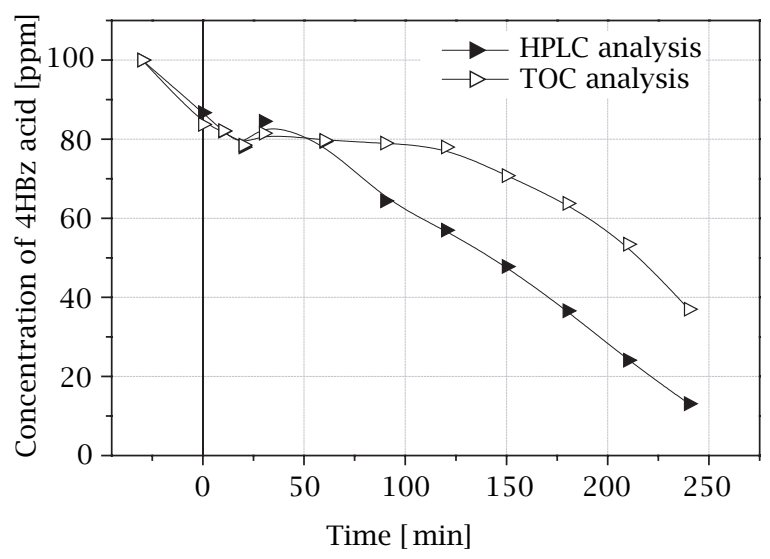

Figure 6. Kinetics of photodegradation of 100 ppm aqueous solution of 4-hydroxybenzoic acid in the presence of Z513 aerogel.

Z516 (60\% IZPT, methanol), while Z513 (the best one in the case of p-chlorophenol photodegradation) was the worst one. Photodegradation of 4-hydroxybenzoic acid in the presence of Z516 was confirmed by total organic carbon analyses (Figure 6, almost 65\% of acid initial concentration was mineralised).

\section{CONCLUSION}

Titania aerogels are white, very light powders. Volumes of mico- and mesopores, surface areas, size of the particles of the aerogels strictly depend on a kind of solvent (isopropanol, methanol) used in the initial step of preparation process. There is no big difference between aerogels prepared from the same solvent but manifold precursor concentrations. Each of the aerogels indicate anatase crystalline phase. The amounts of the phase change in the following order Z513 > Z516 > Z514. The best photocatalytic properties indicated aerogel Z513 (30\% IZPT, isopropanol), whereas Z514 (30\% IZPT, methanol) and Z516 (60\% IZPT, methanol) were similar. Photocatalytic activity of the aerogel Z513 in comparison to commercial $\mathrm{TiO}_{2} \mathrm{P} 25$ was almost identical. However, structures of them are quite different (small particles of $\mathrm{TiO}_{2} \mathrm{P} 25$ and the big of $\mathrm{Z} 513$, twice smaller BET surface of $\mathrm{TiO}_{2}$ P25 than of $\mathrm{Z513}$, differences in the size of the pores). Taking into consideration obtained results in this study the conclusion can be drawn that photocatalytic activities do not depend neither on surface area, size and volumes of the pores nor on the size of agglomerates. The one reason of good photocatalytic properties of Z513 in the case of p-chlorophenol degradation can be the largest content of anatase phase in comparison to the others aerogels. It is also necessary to considerate influence of the kind of reagent on photocatalytic properties of the aerogels, while the research proved that the best selectivity towards 4hydroxybenzoic acid indicated aerogel Z516 (60\% IZPT, methanol).

The objects of the next studies are to prepare an universal aerogel indicating good photocatalytic properties for a group of pollutants present in the water and to examine the intermediates products of $\mathrm{p}$ chlorophenol photodecomposition.

\section{ACKNOWLEDGEMENT}

We would like to thank Dr Inz. Barbara Pniak from Wroclaw University of Technology for helpful hints.

\section{REFERENCES}

[1] G. Dagan and M. Tomkiewicz, J. Non-Cryst. Sol. 175 (1994), 294.

[2] R. W. Mattews, Proceedings of the $1^{\text {st }}$ International Conference on $\mathrm{TiO}_{2}$, Canada 8-13 November, 1993, pp. 121-138.

[3] J. Villasenor, D. Reyes, and G. Pecchi, J. Chem. Technol. Bio. 72 (1998), 105.

[4] M. C. Markham and K. L. Laidler, Kinetics of photooxidation on the surface of Aqueous ZnO, 1953.

[5] J. H. Herrmann, Cat. Tod. 53 (1999), 115.

[6] A. Sclafani, L. Palmisiano, G. Marci, and A. M. Venezia, Solar Energy Materials and Solar Cells 51 (1998), 203.

[7] C. A. Martin, M. A. Baltanes, and A. E. Cassano, Cat. Tod. 27 (1996), 221.

[8] M. Trillas, J. Peral, and X. Domenech, Appl. Cat. B: Env. 5 (1995), 377.

[9] A. M. Peiró, J. A. Ayllón, J. Peral, and X. Domenech, Appl. Cat. B: Env. 30 (2001), 359. 
[10] T. Pandiyan, O. Martinez Rivas, J. Orozco Martinez, G. Burillo Amezcua, and M. A. Martinez-Carrillo, J. Photochem. Photobio. A: Chem. 146 (2002), 149.

[11] D. Robert and J. V. Weber, J. Clean Prod. 6 (1998), 335.

[12] M. S. Ahmed and Y. A. Attia, J. Non-Cryst. Sol. 186 (1995), 402.

[13] A. Fujishima, T. N. Rao, and A. D. Tryk, J. Potoch. Photobiol. C: Photoch. Rev 1 (2000), 1.

[14] J. Walendziewski, M. Stolarski, M. Steininger, and B. Pniak, React. Kinet. Catal. Lett. 66(1) (1999), 71.

[15] B. Sen, M. A. Vannice, J. Cat. 113 (1998), 52.

[16] Z. Deng, J. Wang, Y. Zhang, Z. Weng, Z. Zhang, B. Zhou, J. Shen, and L. Cheng, Nanostr. Mat. 11(8) (1999), 1313.
[17] M. Schneider and A. Baiker, Cat. Tod. 35 (1997), 339.

[18] X. Zili, et al., Mat. Scien. Eng. B 56 (1999), 211.

[19] P. Stefchev, et al., Int. J. Inorg. Mat. 3 (2001), 531.

[20] M. Formenti, F. Juillet, P. Meriaudeau, and S. J. Teichner, Bull. Soc. Chim. Fr. 35 (1972), 69.

[21] M. Hügül, I. Boz, and R. Apak, J. Haz. Mat. B: 64 (1999), 313.

[22] A. Sedykh, R. Saiakhov, and G. Klopman, Chemosphere 45 (2001), 971. 


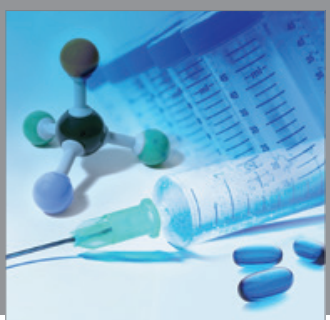

International Journal of

Medicinal Chemistry

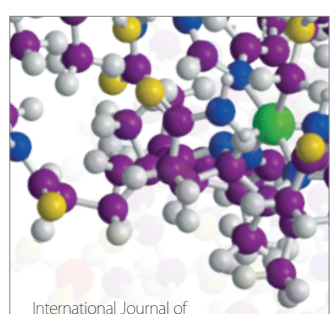

Carbohydrate Chemistry

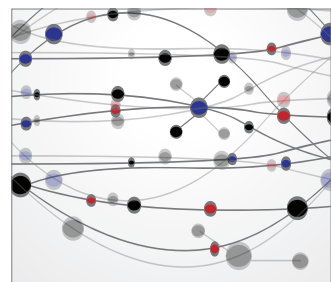

The Scientific World Journal
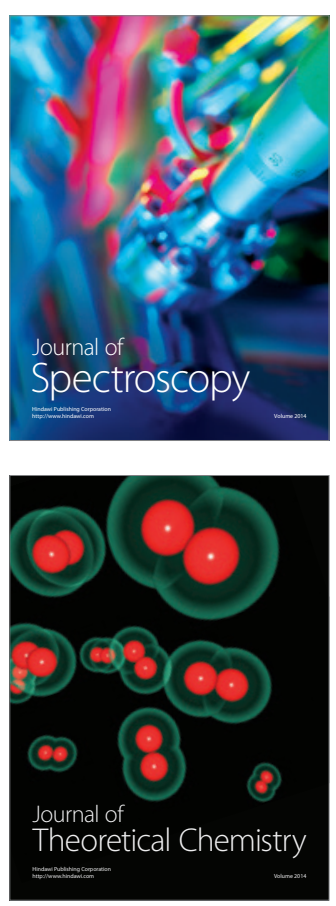
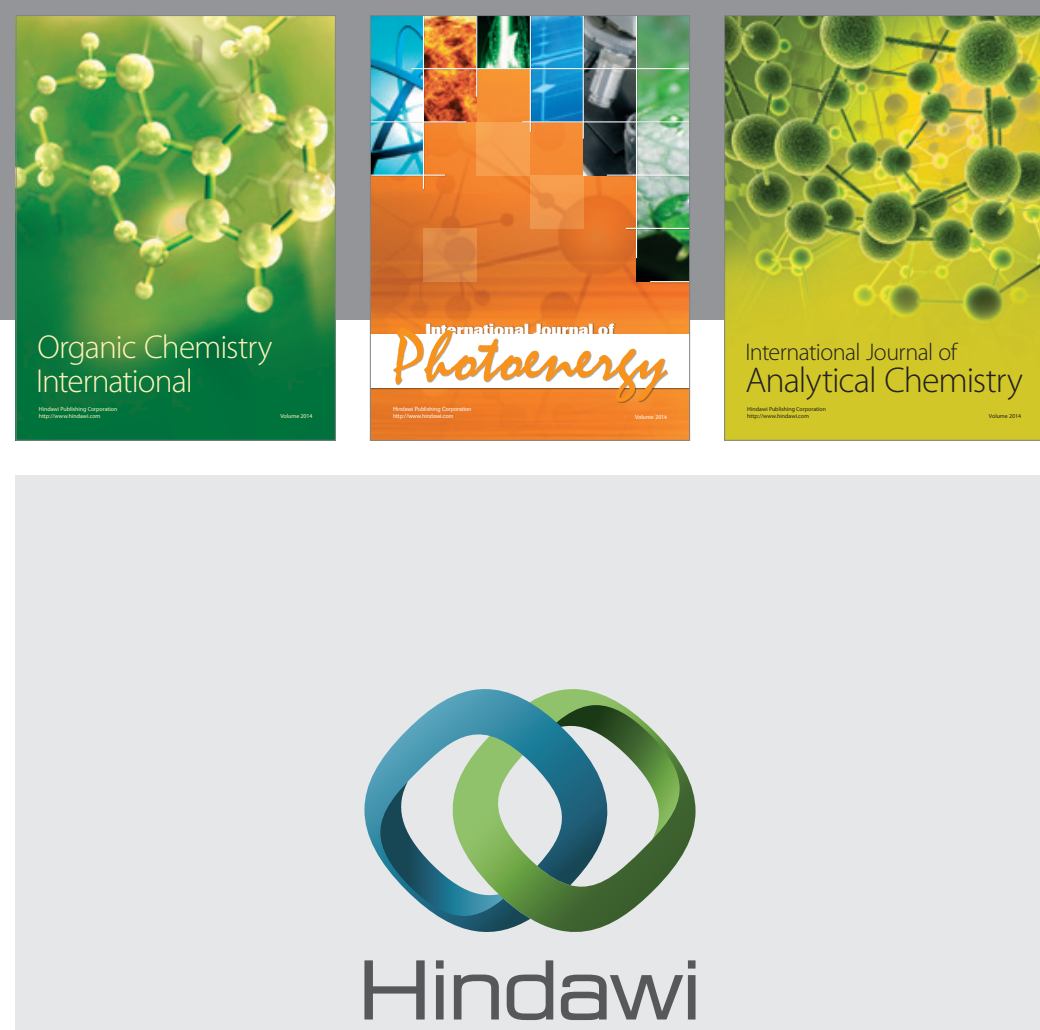

Submit your manuscripts at

http://www.hindawi.com
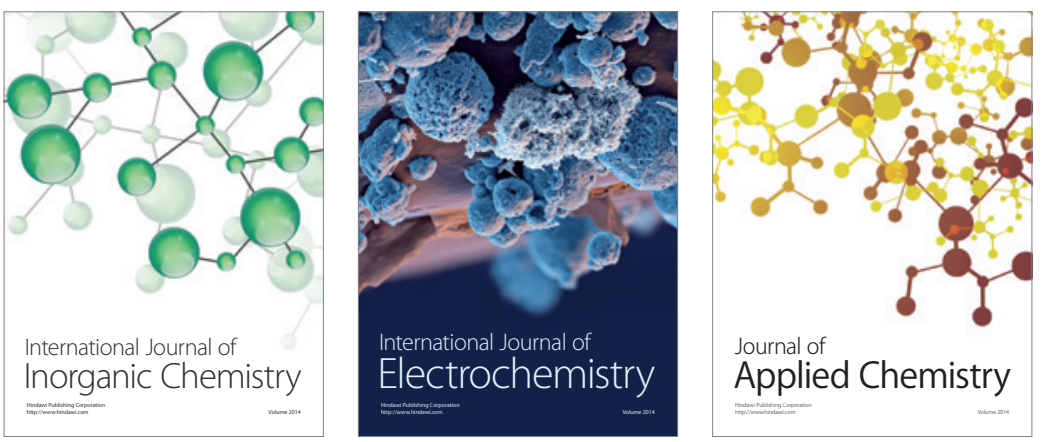

Journal of

Applied Chemistry
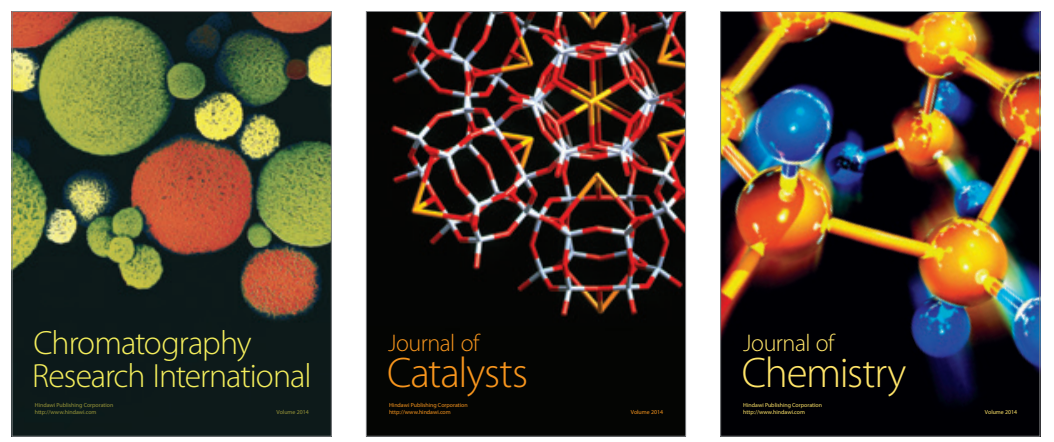
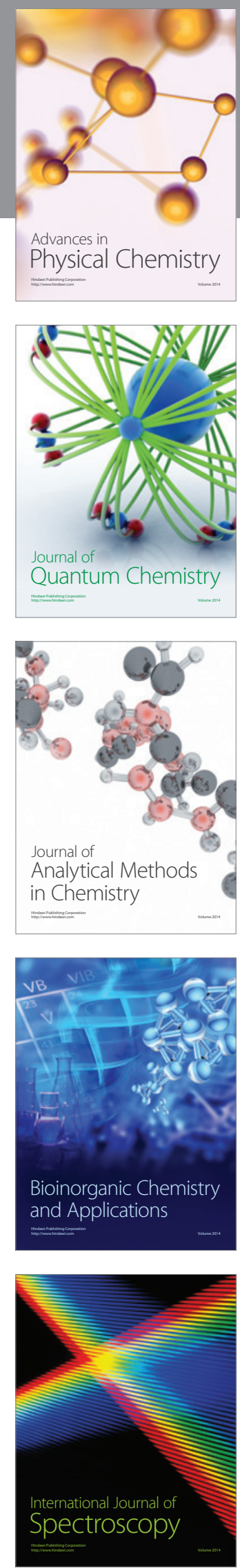